\title{
EDUCAÇÃO CONSCIENTIZADORA DO IDOSO DIABÉTICO: UMA PROPOSTA DE INTERVENÇÃO DO ENFERMEIRO*
}

\author{
EDUCATION DIRECTED TO RAISE THE CONSCIOUSNESS OF ELDERLY \\ PATIENTS WITH DIABETES: A NURSES' INTERVENTION PROPOSAL
}

\author{
EDUCACIÓN CONSCIENTIZADORA DEL ANCIANO DIABÉTICO: UNA \\ PROPUESTA DE INTERVENCIÓN DEL ENFERMERO
}

Darlene Mara dos Santos Tavares** Rosalina A. Partezani Rodrigues***

Tavares DMS, Rodrigues RAP. Educação conscientizadora do idoso diabético: uma proposta de intervenção do enfermeiro. Rev Esc Enferm USP 2002; 36(1): 88-96.

\section{RESUMO}

Este estudo teve como objetivo identificar as necessidades educativas dos idosos, de acordo com as suas percepcões, elaborando uma proposta educativa. Os dados foram coletados de setembro de 96 a março de 97 e a amostra constituiu-se de 26 idosos diabéticos cadastrados na Associação dos Diabéticos de Uberaba - M.G. Utilizou-se a observação participante e a entrevista semi estruturada. Os dados foram analisados de acordo com os pressupostos dos temas geradores, segundo Paulo Freire. Os resultados mostraram que a Associação dos Diabéticos tem como objetivo a educação em saúde de seus freqüentadores. Emergiram quatro temas geradores: Diabetes mellitus tipo 2, Atenção nos serviços de saúde, Doenças associadas e O idoso diabético.

PALAVRAS-CHAVE: Educação. Idoso. Diabetes mellitus.

\begin{abstract}
The purpose of this study was to identify educative needs of elderly people according to their perceptions elaborating an educative proposal. Data were colleted from September 1996 to March 1997 and this sample was formed by 26 elderly patients with diabetes, which were members of the Association of Patients with Diabetes of Uberaba - M.G.. Authors utilized the participant observation and semi-structured interview. Data were analysed according to the presupposition of the generator themes proposed by Paulo Freire. The results showed that the Association of Patients with Diabetes aims at their health education. Four generator themes emerged: , Diabetes Mellitus type 2, Attention in Health Services, Associated Diseases and the Elderly Patient with Diabetes.
\end{abstract}

KEYWORDS: Education. Elderly patient. Diabetes mellitus.

\section{RESUMÉN}

Este estudio tuvo como objetivo identificar las necesidades educativas de los ancianos, de acuerdo con sus percepciones, elaborando una propuesta educativa. Los datos fueron recoleccionados entre septiembre de 1996 y marzo de 1997 y la muestra fue formada por 26 ancianos diabéticos registrados en la Asociación de Diabéticos de Uberaba - MG. Fue utilizada la observación participante y la entrevista semi estructurada. Los datos fueron analizados de acuerdo con los presupuestos de los temas generadores, según Paulo Freire. Los resultados mostraron que la Asociación de Diabéticos tiene como objetivo la educación en salud de sus miembros. Emergieron cuatro temas generadores: diabetes mellitus tipo 2, atención en los servicios de salud, enfermedades asociadas y el anciano diabético.

PALABRAS-CLAVE: Educación. Anciano. Diabetes mellitus.

Este trabalho é parte da dissertação de mestrado intitulada "Educação Conscientizadora do Idoso Diabético: uma proposta de intervenção do enfermeiro", junto ao Programa de Pós-graduação, Area Enfermagem Fundamental do Departamento de Enfermagem Geral e Especializada da Escola de Enfermagem de Ribeirão Preto-USP, defendida em 1997.

** Enfermeira. Professora da Faculdade de Medicina do Triângulo Mineiro-FMTM e Universidade de Uberaba

*** Enfermeira. Professor Associado do Departamento de Enfermagem Geral e Especializada da Escola de Enfermagem de Ribeirão Preto-US? - e.mail: rosalina@eerp.usp.br 


\section{INTRODUÇÃO}

No Brasil, a partir da década de 60, ocorreram várias transformações politicas, sociais e econômicas que determinaram, dentre outros fatos, mudanças no perfil demográfico da população, ou seja, "uma população de característica jovem que passa para uma população velha". Verifica-se, portanto, o aumento da expectativa de vida e maior concentração de pessoas idosas na população geral(1).

Concomitante a essas transformações demográficas, ocorreram também as epidemiológicas, que se constituem em mudanças da alta incidência da morbimortalidade por doenças infecciosas e parasitárias, para um predomínio das doenças crônicas não transmissiveis, em especial as cardiovasculares, neoplasias malignas, causas externas, transtornos mentais e diabetes ${ }^{(1)}$.

Nesta perspectiva, a Organização Panamericana de Saúde(2) refere que o aumento gradual da população de idosos e a maior incidência das doenças crônicas representam carga adicional ao sistema de saúde, o que poderá gerar problemas sociais, econômicos, médicos, éticos, criando situações criticas aos países com recursos limitados.

É imprescindivel a tomada de decisões politicas, sociais e de saúde que visem a uma reversão desse quadro, nesta população. De que adianta prolongar a vida do ser humano, se este não pode vivê-la plenamente?

Dentre os problemas de saúde dos idosos, destaca-se o diabetes mellitus tipo 2, que apresenta características específicas em pessoas acima de 65 anos. A partir de 30-40 anos, o homem pode apresentar uma diminuição na tolerância à glicose em jejum, especialmente após as refeições. Este fato pode estar relacionado ao processo de envelhecimento, bem como corresponder a uma etapa evolutiva do desenvolvimento do diabetes mellitus a ser instalado(3).

O autor acima mencionado coloca que, em geral, o diabetes mellitus no idoso é pouco sintomático e de começo insidioso devendo-se, em parte, ao aumento do limiar renal para a glicose. Assim, as hiperglicemias moderadas (220-250 mg/dl) não são acompanhadas de glicosúria, o que justifica a falta de poliúria e polidpsia. Seu estudo demonstrou que o diagnóstico do diabetes em idosos é feito, em $78 \%$ dos casos, através de exames de rotinas, em $8 \%$ por complicações do diabetes, e em 14\% por sindrome diabética aguda. Essas taxas corresponderam, em pessoas abaixo de 65 anos com diabetes mellitus tipo 2, a 25\%, 25\% e $50 \%$ respectivamente.

Ressalta-se que o seu destaque também está relacionado à contribuição que vem dando às causas de óbitos no Brasil. Turner(4); Zimmet citado por Martins relatam que as "doenças cardiovasculares, dislipidemias, hipertensão, obesidade e diabetes mellitus formam um conjunto de morbidades geralmente associadas entre si". No Brasil, em 1985, um terço das mortes foi devido a essas doenças.

Laurenti(5) realizaram um estudo, no municipio de São Paulo, demonstrando que a taxa de mortalidade por diabetes mellitus, no período de 1900 a 1960, apresentou um acréscimo de treze vezes. Posteriormente, esses autores analisaram os atestados de óbitos, no período de 1974 a 1975 e constataram que o diabetes mellitus foi a causa básica de morte em $2,11 \%$ e, como causa associada, representou $10,8 \%$ dos casos de 15 a 74 anos de idade.

Estudo realizado por Lessa(6) também afirma que houve aumento na taxa de mortalidade, por diabetes, no decorrer dos anos. Relata ainda que, no período de 1950 a 1975, essa doença teve um aumento médio proporcional, nas capitais brasileiras, de 3,4 vezes, e entre 1977 e 1985, de 1,5 vezes.

No estudo multicêntrico sobre prevalência do diabetes mellitus, realizado no Brasil, verificou-se que o aumento de prevalência do diabetes ocorre proporcionalmente à idade. Os autores deste estudo alertam para a importância dessa enfermidade, em razão do envelhecimento populacional que vem ocorrendo no Brasil. Reforçam também que essa constatação corrobora com estudos realizados em países desenvolvidos e em desenvolvimento(7).

Nesta perspectiva, o Ministério da Saúde(8) pontua, de maneira geral, a influência do diabetes na saúde da população, quando não controlada eficazmente. Relata que:
"essa doença é uma das principais causas de internação no Brasil; uma pessoa diabética tem dezessete vezes mais chance de desenvolver nefropatia e quarenta vezes mais chance de sofrer amputação de membros inferiores; o infarto cardiaco é seis vezes mais freqüente no diabético e o acomete dez anos antes do que na população geral; é uma das causas de impotência sexual masculina; cerca de $50 \%$ dos diabéticos são hipertensos contra 10 a 15\% da população geral; quando o diabetes surge antes dos 50 anos, o paciente perde de cinco a quinze anos de expectativa de vida".

De acordo com o Ministério da Saúde(8), no Estado de Minas Gerais, existiria cerca de 300.000 pacientes diabéticos (tipo 1 e 2), representando 1,9\% da população total; destes, 2,6\% seria do tipo 1 e $97,4 \%$ do tipo 2. Sabe-se que a prevalência do diabetes apresenta um aumento de aproximadamente 15\% nos idosos; assim, estima-se que Minas Gerais tenha em torno de 51.976 diabéticos com idade acima de 69 anos, o que significa $17,33 \%$ da população idosa. 
O diabetes figura, hoje, como um dos grandes problemas de Saúde Pública, quer seja nas questões sociais, econômicas, familiares e também pessoais.

Considerando o aumento percentual de idosos na população associada às doenças crônicas não transmissiveis, o Ministério da Previdência e Assistência Social(9), através da Política Nacional do Idoso, sugere como ações prioritárias: realizar estudos sobre epidemiologia das doenças no idoso e, a partir disso, propor serviços de atenção à saúde, visando à promoção, proteção e recuperação da saúde, bem como a prevenção de doenças do idoso. Ressalta ainda a importância de implementar programas educativos aos idosos, favorecendo a estes o autocuidado à saúde, prevenindo incapacidades e postergando a morte.

Nesta perspectiva, acredita-se que as ações educativas, junto ao paciente, família e comunidade, têm um papel essencial no controle dessa enfermidade, uma vez que suas complicações estão estritamente ligadas ao conhecimento para o cuidado pessoal diário adequado e ao estilo de vida saudável. O idoso, em especial, necessita ser estimulado pelos profissionais de saúde a manter uma vida independente, adaptandose da melhor maneira possivel às modificações exigidas para o controle metabólico. As ações educativas terão muito a contribuir para uma melhor qualidade de vida; entretanto, algumas questões devem ser consideradas para se obter resultados efetivos, como a fase do ciclo vital e suas peculiaridades(10). A vida adulta compreende três momentos: o adulto jovem, o adulto médio e o adulto velho. Portanto, para elaborar uma proposta educativa junto aos idosos buscou-se um referencial na educação de adultos.

Na década de 60, o educador Paulo Freire teve um grande destaque no país ao propor seu método de ensino, que não visava apenas a alfabetização, mas também a conscientização, que segundo ele "consiste no desenvolvimento critico da tomada de consciência"(11)

Desta forma, estudiosos têm procurado aliar as peculiaridades destas fases - adultos e idosos - com as tecnologias educativas, rompendo com a forma tradicional de educação, baseada apenas na transmissão do conhecimento. O adulto ocupa um lugar de destaque no processo educativo, sendo elemento ativo e participativo em todas as fases, desde seu planejamento até sua avaliação.

A Organização Mundial de Saúde (OMS) reconhece a importância das atividades educativas junto aos pacientes portadores de doenças crônicas não transmissiveis, bem como a participação da família e da comunidade. Assim, a OMS tem proposto várias reuniões para a discussão dessa temática, procurando desenvolver métodos inovadores e mais efetivos, bem como elaborado materiais instrucionais para a educação do paciente(12).
Contextualizando a educação no âmbito da enfermagem, constata-se que as colocações do Ministério da Saúde se reproduzem. A prática profissional mostra que o enfermeiro não tem incorporado a educação do paciente como uma atividade relevante no desenvolvimento de suas atribuições, verificando que, quando essas ações são realizadas, nem sempre se obtém resultados favoráveis.

A observação da prática mostra que o enfermeiro é o elemento da equipe multiprofissional que tem maior probabilidade de acompanhar as condições de saúde e doença do paciente, de maneira mais próxima. Mas vê-se que este encontra-se bastante absorvido pelas demandas administrativas, que o têm distanciado da assistência direta do paciente. Por outro lado, o preparo do enfermeiro enquanto educador de saúde tem deixado algumas lacunas. Diante dessas situações, cabe fazer aqui uma reflexão do trabalho do enfermeiro acerca do desenvolvimento de suas ações em saúde.

Sabe-se que, para o diabetes, é essencial o controle dos níveis glicêmicos, o que pode determinar a ocorrência ou não das complicações advindas dessa doença. Neste contexto, o enfermeiro, estando mais próximo e capacitado para o desenvolvimento das atividades educativas efetivas, muito poderá fazer para o controle desta doença e para a promoção da saúde deste grupo.

Atenta a essas questões e às outras colocadas no decorrer deste estudo, optou-se por elaborar uma proposta educativa, após a identificação das necessidades dos idosos diabéticos, que leve em consideração a conscientização do aprendiz, fazendoo sujeito da sua própria aprendizagem. Para tanto, norteou-se nos seguintes objetivos: identificar as necessidades educativas em saúde das pessoas idosas diabéticas tipo 2, que freqüentam a Associação dos Diabéticos, de acordo com a visão destes e elaborar propostas educativas de acordo com as necessidades identificadas e adequadas ao seu desenvolvimento na referida instituição.

\section{PROCEDIMENTO METODOLÓGICO}

Este é um estudo descritivo de natureza quantiqualitativo, voltado para a intervenção educativa junto aos idosos diabéticos, a partir de necessidades identificadas.

A população constituiu-se de sujeitos com 60 anos de idade e mais, com diabetes mellitus tipo 2 freqüentadores da Associação dos Diabéticos do município de Uberaba - MG.

A Associação dos Diabéticos foi fundada em 03 de abril de 1992. Seu objetivo é: "assistir ao 
diabético, orientá-lo, bem como sua familia no que concerne aos aspectos material, moral e educacional, promovendo sua reabilitação, sempre que possivel."

Localiza-se em uma região central do município. Seu atendimento ao público é de segunda a sexta-feira, no horário de 07:00 h às 11:30 h. e de 13:00 h às 16:00 h. Atende diabéticos do município e do Vale do Rio Grande. No local, há uma sala destinada à Associação dos Renais.

Trata-se de uma instituição filantrópica afiliada à Fundação de Ensino e Pesquisa Uberaba - FUNEPU, que coopera com o pagamento das contas de água, luz e o aluguel da casa onde funciona a Associação. Para sua manutenção, recebe também auxilio da prefeitura.

A Associação cadastra todas as pessoas que procuram o local e que desejam fazê-lo, porém não existe uma atualização sistemática do mesmo.

Tal fato pode estar relacionado aos custos exigidos para o tratamento e controle desta doença e à dificuldade encontrada, pela população, em ter acesso aos serviços de saúde e aos medicamentos.

Para ampliar o atendimento aos diabéticos, a Associação possui "parcerias" com outros serviços, através do encaminhamento e recebimento de clientes como: o Uberaba Tênis Clube, para a realização de atividades fisicas coerentes com a enfermidade em pauta e o Hospital Escola, para atendimento no serviço de orientação nutricional e no ambulatório de endocrinologia, de clientes que estão "passando mal". A FUNEPU fornece tratamento com psicólogos.

Os dados foram coletados em duas etapas: a primeira constituída pela observação participante do funcionamento da Associação dos Diabéticos, segundo Spradley (1980), adaptado por Domingues(13).

As observações foram realizadas nos meses de dezembro de 1996 a fevereiro de 1997, totalizando dez sessões de quatro horas cada, no período da manhã, consideradas suficientes em razão de sua saturação. As anotações foram registradas em diário de campo, imediatamente após a observação.

$\mathrm{Na}$ segunda etapa, utilizou-se a entrevista com os idosos diabéticos. O roteiro de entrevista, após sua elaboração, foi testado mediante entrevistas piloto e apresentado a três juizes para sua adequação e validação. As entrevistas foram gravadas, após a autorização dos entrevistados, e transcritas imediatamente após sua realização. Para melhor compreensão das falas do entrevistado, o entrevistador esteve atento também às comunicações não verbais.

As entrevistas foram realizadas na Associação dos Diabéticos, durante o periodo de setembro de 1996 a março de 1997, aguardando a chegada espontânea do idoso, totalizando vinte e seis sujeitos, sendo que não houve recusa. A constituição da amostra deveu- se à saturação dos dados coletados, isto é, em pesquisa qualitativa, o interesse é no fenômeno da situação encontrada. Aos entrevistados foram colocados os objetivos e a natureza desta investigação; também foi solicitada oralmente a colaboração destes para participação na mesma, deixando-os livres para emitirem suas opiniões, garantindo-lhes o sigilo e o anonimato de suas respostas.

A análise dos dados desenvolveu-se em duas etapas: $1^{\circ}$ etapa- Realização da análise descritiva do funcionamento da Associação dos Diabéticos; 2a etapa - Realização da análise temática, utilizandose das falas descritas das entrevistas dos idosos. Para tanto, baseou-se nos pressupostos da análise temática, proposto por Freire (11), seguindo as fases descritas abaixo:

Levantamento do universo temático: 1 Fase - Levantamento dos temas geradores -- realização de entrevista semi-estruturada, onde o entrevistador dialogou, de maneira informal, com os entrevistados, possibilitando a esses verbalizarem as necessidades educativas de saúde; $\mathbf{2}^{\boldsymbol{a}}$, Fase - Organização $e$ exploração do material obtido - as entrevistas obtidas foram transcritas e lidas exaustivamente, verificando sua adequação aos objetivos propostos. A seguir, foram identificadas e agrupadas as frases e parágrafos repetidos e que possuíam elementos comuns, observando sua freqüência; $3^{0}$ Fase - Seleção $e$ codificação de frases e parágrafos registrados - as frases e parágrafos foram codificados e agrupados emergindo os temas geradores; $4^{\circ}$ Fase - Síntese das frases e parágrafos selecionados - os temas geradores, identificados nas fases anteriores, foram reagrupados em quatro grandes temas geradores.

Elaboração da proposta educativa: $1^{a}$ Fase Seleção dos temas geradores- selecionou-se os temas geradores, produzidos na entrevista com os idosos, de acordo com a sua freqüência e a riqueza temática; $2^{a}$ Fase - Planejamento da atividade educativa - a partir dos temas geradores, emergiu a proposta educativa, segundo o modelo pedagógico de Paulo Freire, considerando a pertinência de seu desenvolvimento na Associação dos Diabéticos.

\section{RESULTADOS}

\section{Características sócio-econômicas-demográficas dos idosos diabéticos da amostra estudada}

Foram realizadas vinte e seis entrevistas, como já mencionado anteriormente, das quais 20 (76,92\%) são do sexo feminino e $6(23,07 \%)$ do masculino. A faixa etária que apresentou maior proporção foi entre $60 \dot{u}^{3 / 4} 70$ anos com 16 idosos $(61,54 \%)$ e a menor foi

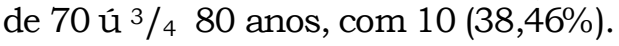


Em relação à escolaridade, 22 (84,61\%) idosos possuíam $1^{\circ}$ grau incompleto, $03(11,54 \%)$ são analfabetos e apenas $01(3,85 \%)$ possuía $2^{\circ}$ grau completo.

Ao serem questionados sobre sua profissão, 23 $(50 \%)$ idosos realizam trabalhos domésticos em suas próprias casas, $11(42,30 \%)$ são aposentados, entretanto $02(18,18 \%)$ destes trabalham, para complementarem sua aposentadoria e $02(7,70 \%)$ não tinham aposentadoria e trabalham fora do lar.

Quanto à renda individual, a maioria dos idosos diabéticos recebe baixos salários, estando concentrados em: $13(50 \%)$ entre $111^{3} / 43$ salários minimos, e 08 (30,77\%) sem renda. Fato este que pode estar relacionado às idosas que trabalham no lar e não recebem salários, dependendo assim da renda familiar para sua sobrevivência.

Ao observar a renda familiar, constata-se uma ligeira variação cuja maior concentração está entre $16^{3} / 43$ salários mínimos com 10 idosos $(38,46 \%)$ e 09 $(34,61 \%)$ entre $311^{3} / 46$ salários minimos.

No entanto, ao verificar a estrutura familiar dos idosos diabéticos, obtém-se que 19 (73,07\%) vivem com o cônjuge e/ou filhos, 05 (19,23\%) vivem só e 02 $(7,70 \%)$ moram com outros elementos da família.

Ao desmembrar-se o número de pessoas da estrutura familiar, verifica-se que a maioria dos idosos $16(61,54 \%)$ mora com 1 a 3 pessoas. Entretanto, vêse que as famílias grandes, anteriormente comuns no país, estão pouco representadas, 05 (19,23\%), igualando aos idosos que moram sós.

Em relação ao número de filhos que os idosos diabéticos tiveram, obteve-se que 09 (34,61\%) destes tiveram de 1 a 3 filhos, 07 idosos (26,93\%) tiveram de 7 a 10 filhos, 06 idosos (23,08\%) tiveram de 4 a 6 filhos e 04 idosos $(15,38 \%)$ não tiveram filhos.

Em relação ao estado civil, 14 (53,84\%) são casados/amasiados, 07 (26,93\%) são viúvos e 05 $(19,23 \%)$ estão representados por outros, ou seja, solteiros, desquitados.

Para a elaboração da proposta educativa, optouse dentro da educação de adultos, pelo modelo pedagógico de FREIRE' (1993), que se sustenta no diálogo, na participação e na criticidade.

Após análise das entrevistas emergiram quatro temas geradores apresentados abaixo, que foram considerados possiveis da atuação educativa do enfermeiro.

Tema 1 - Diabetes mellitus tipo 2: este tema compreendeu todos os sub-temas que estavam relacionados à enfermidade em questão. Praticamente, todos os aspectos sobre o diabetes mellitus emergiram, englobando sinais, sintomas, etiopatogenia, diagnóstico, tipos de tratamento, complicações, educação em saúde e os fatores emocionais decorrentes do seu acometimento. Os sub-temas encontrados são: desconhecimento de alguns aspectos do diabetes mellitus; restrição alimentar; presença de sintomas de descontrole metabólico do diabetes mellitus; atividade física; busca de informação; sentimento negativo frente ao diabetes mellitus; tratamento medicamentoso; diagnóstico casual; presença de complicações do diabetes mellitus.

Tema 2 - Atenção nos serviços de saúde: este tema correspondeu ao reagrupamento dos sub-temas que se referiam à organização dos serviços de saúde, à forma como os idosos diabéticos eram atendidos nestes locais, os tipos de informações recebidas e a valorização de tais instituições, por estes sujeitos. Seus sub-temas são: informações oferecidas nos serviços de saúde; serviço de saúde; atendimento do serviço de saúde.

Tema 3 - Doenças Associadas: este tema englobou as frases e parágrafos registrados que emergiam as diversas enfermidades associadas ao diabetes mellitus, das quais estavam acometidos os idosos. Apresentase o seu sub-tema: doenças associadas

Tema 4 - 0 idoso diabético: este tema relacionou os sub-temas: auto-imagem; apoio familiar; crenças; perspectivas futuras; desengajamento social.

\section{DISCUSSÃO DOS DADOS: A EDUCAÇÃO CONSCIENTIZADORA DE PAULO FREIRE}

A maioria da população estudada apresenta baixo nivel de instrução. Tal fato deve ser considerado, no momento de elaborar a proposta, educativa, procurando adequar a linguagem e os recursos de ensino a esta situação dos idosos diabéticos, possibilitando uma comunicação efetiva entre o "coordenador de grupo" e os mesmos.

No que concerne à estrutura familiar dos idosos diabéticos, pode-se considerar que, embora a renda familiar tenha um ligeiro acréscimo em relação à individual, o número de membros que depende desta renda também é maior. Trata-se de um dos fatores que figura entre as dificuldades encontradas no controle e tratamento do diabetes, visto que a dieta alimentar e os medicamentos, quando não oferecidos pelo serviço de saúde, poderão significar um acréscimo nas despesas familiares.

Outra questão a ser levantada, está relacionada à etiopatogenia do diabetes mellitus tipo 2. Sabe-se que, dentre os fatores que podem levar ao acometimento desta enfermidade, encontra-se a hereditariedade. Portanto, o envolvimento dos filhos dos idosos diabéticos no tratamento é relevante, inclusive para a própria prevenção destes, através de atividades educativas que procurem diminuir os fatores 
precipitantes desta doença, como o sedentarismo, alimentação rica em carboidratos concentrados e outros.

Os dados acerca do estado civil, ainda que não possam ser generalizados para a Associação dos Diabéticos, acompanham o estudo de Veras(14) realizado no Brasil. Este demonstra que o percentual de mulheres idosas casadas é significativamente menor que o percentual de homens idosos.

Cabe ressaltar, também, que o envelhecimento não altera a capacidade de aprendizagem do idoso. Percebe-se, no decorrer dos anos, um declinio na atividade física, na visão, na audição, no olfato, no tato e na habilidade da fala, entretanto, não se observa um declínio na função intelectual do idoso. Pesquisas como as de Withnall, Kabwasa(15) e Milligan(16) têm mostrado que pessoas com mais de 65 anos de idade são capazes de aprender, porém alguns aspectos devem ser considerados. Dentre estes, a saúde do idoso para permitir a realização da aprendizagem, a facilitação da aprendizagem do idoso que pode ser feita através da abordagem centrada nos problemas dos mesmos, com o aumento do auto-conceito do idoso, promoção da autonomia, material didático claro, ambiente agradável, oportunidade e tempo para a prática, dando oportunidade aos idosos para refletirem sobre suas experiências enquanto diabéticos e também estimulálos para se envolverem no diagnóstico e tratamento. Além disso, o idoso deve envolver-se no planejamento, na ação, na avaliação das necessidades de aprendizagem, na organização do material, de forma que auxilie na memorização e nos diferentes contextos de aprendizagens como leituras, seminários, trabalhos práticos e outros ${ }^{(16)}$.

Segundo Freire(11), é possivel os adultos passarem de uma consciência intransitiva, que: "se caracteriza pela quase centralização dos interesses do homem em torno de formas mais vegetativas de vida", para a consciência transitiva, que é evidenciada pela: "simplicidade na interpretação dos problemas", "pela tendência a julgar que o tempo melhor foi o tempo passado", "pela fragilidade na argumentação", "pela prática não propriamente do diálogo, mas da polêmica".

A consciência critica que esse autor pretende obter, "se caracteriza pela profundidade na interpretação dos problemas, pela substituição de explicações mágicas por principios causais", "por despir-se ao máximo de preconceitos na análise dos problemas e na sua apreensão, esforçar-se por evitar deformações", "pela prática do diálogo e não da polêmica".

Contextualizando a educação no âmbito da saúde, verifica-se que o idoso diabético é tratado como uma pessoa que recebe, passivamente, o nosso conhecimento sobre a sua doença, a dieta adequada, tratamento necessário, desvinculado de sua realidade, de suas possibilidades de aprendizagem, de suas condições econômicas, sociais e emocionais para aderir ao tratamento.

O método de Paulo Freire abordou uma alfabetização direta, de maneira que as experiências dos trabalhadores fossem compativeis com o material de aprendizagem, e que esta fosse um ato de criação e gerasse outros atos criadores. O homem deveria ser um membro ativo do processo de ensino-aprendizagem; o método educativo seria um instrumento do educando eque este identificasse o conteúdo da aprendizagem com o processo de aprender; enfim, que o homem fosse o sujeito de sua própria educação(11).

Percebe-se nos vários trabalhos de Freire", que o pedagogo brasileiro reforça a necessidade, imprescindivel, do diálogo na educação. Refere que a relação dialogal se inicia quando educador-educando definem sobre o que dialogar. Assim, o conteúdo programático é a "devolução organizada, sistematizada e acrescentada ao povo daqueles elementos que este lhe entregou de forma desestruturada."

Norteada por estes pressupostos, iniciou-se a coleta dos dados. Como relata Freire(11), "as entrevistas revelam anseios, frustrações, descrenças, esperanças e impeto de participação". Estar atento aos temas emergidos dos sujeitos que convivem com a enfermidade, respeitar suas crenças, seus sentimentos e sua cultura são passos valiosos que o educador em saúde dá direcionados à realização de atividades educativas efetivas.

Segundo ferreira(17), domesticar tem o significado de domar, que está ligado a subjugar, sujeitar, reprimir; consciência é definida como atributo pelo qual o homem pode conhecer e julgar sua própria realidade. Esses termos possuem significados contrários; então no momento de se realizar uma atividade educativa, é necessário que o educador tenha claro qual o resultado que se espera obter. A concepção que o profissional tem sobre educar irá influenciar na escolha de estratégias de ensino e conseqüentemente em seus resultados.

Coles(10), refere que as doenças crônicas requerem um atendimento centrado no cliente, diferentemente do que se observa na prática profissional. Atualmente, o profissional de saúde entende o seu papel como "identificar $e$ resolver problemas". Assim, o sucesso do tratamento estaria nas mãos do cliente, ou seja, que este aceite subjugarse à prescrição médica. Entretanto, descreve que o atendimento deve ser considerado mais uma definição de problema e que a interação do profissional de saúde com o cliente permita ao último uma compreensão do seu problema de saúde e as atitudes que se deve ter para controlá-las efetivamente. 
Reconhece-se que a educação em saúde tem um papel importante no tratamento e controle das doenças crônicas. Através desta o cliente poderá sentir-se mais seguro e enfrentar melhor sua enfermidade, procurando adequar sua vida às necessidades advindas do tratamento, da forma menos traumática possível.

Para se conseguir esse equilíbrio, as ações educativas devem não apenas transferir conheci-mentos, mas sim propiciar um convivio estreito com o coordenador de grupo, para que o cliente possa expor seus anseios e suas necessidades. Freire(11) descreve que as atividades educativas nunca devem ser dissertações ou doações de conteúdos. "Nosso papel não é falar ao povo sobre nossa visão do mundo, ou tentar impô-la a ele, mas dialogar com ele sobre a sua e a nossa."

No que tange às pesquisas na área de enfermagem, vários estudos têm mostrado a efetividade das ações educativas, baseadas na conscientização, na prevenção de enfermidades, bem como no controle das mesmas.

Para que o cliente tenha uma participação ativa no processo saúde-doença, é necessário não apenas que este aceite e entenda sua condição, mas também que seja capaz de intervir na mesma. Reconhecer sintomas que requerem atenção médica, a importância da adesão ao tratamento e prevenir incapacidades são ações que devem ser priorizadas na atenção à saúde ${ }^{(12)}$.

A proposta educativa, a ser elaborada, realizarse-á na Associação dos Diabéticos, cabendo, portanto discutir sua viabilidade. Considerando que esta instituição tem como objetivo "assistir ao diabético, orientá-lo, bem como sua família no que concerne aos aspectos material, moral e educacional, promovendo sua reabilitação, sempre que possivel", que há abertura por parte desta em receber profissionais capacitados para trabalhar com atividades educativas, que existe uma demanda de participantes que buscam informações sobre sua enfermidade e que existe um espaço físico (sala de recepção) para o seu desenvolvimento, conclui-se pela possibilidade da realização de educação em saúde na Associação dos Diabéticos com pequenos grupos de idosos diabéticos.

A proposta educativa emergiu das entrevistas com os idosos diabéticos, como descreve Freire(11)... do pensamento-linguagem do homem referido à realidade, os níveis de sua percepção desta realidade, a sua visão do mundo em que se encontram envolvidos seus temas geradores", apresenta-se a seguir a proposta educativa baseada nos 4 temas geradores:

\section{Tema 1: Diabetes mellitus tipo 2}

Objetivo Geral: Possibilitar aos idosos diabéticos complementar seus conhecimentos sobre os diversos aspectos do diabetes mellitus tipo 2, favorecendo o desenvolvimento de atitudes de autocuidado e autocontrole com a sua saúde.

\section{Objetivos especificos:}

vida;

- identificar o impacto do diabetes mellitus na sua

- descrever genericamente o diabetes mellitus: sinais, sintomas e fisiopatologia;

- relacionar as causas e fatores de risco e precipitantes do diabetes mellitus;

- discorrer sobre as formas de tratamento do diabetes mellitus: dietoterapia alimentar, uso de medicamentos, atividades fisicas, e seus beneficios para a saúde;

- listar as complicações advindas do diabetes mellitus, relacionando-as à sua situação de saúde,

- expor os tipos de exames preventivos das complicações do diabetes mellitus.

\section{Conteúdo Programático:}

Noções básicas sobre diabetes mellitus tipo 2 .

\section{Estratégias de ensino:}

Para cada objetivo específico propor:

- socialização das experiências vividas pelo grupo;

- síntese, no quadro de giz, dos pontos emergidos no grupo, destacando ações contraditórias e seus resultados;

- discussão, em grupo, dos pontos destacados pelo coordenador;

- exposição dialogada, pelo coordenador do grupo, do embasamento científico do tema que está sendo trabalhado,

- esclarecimento dos pontos que não ficaram claro para o grupo.

\section{Referências Bibliográficas:}

Ministério da Saúde (BR). Orientações básicas para o diabético. Brasília; 1993.

Hendrikx HM. Diabetes: como reconquistar a doçura da vida. São Paulo: Arte Impressa N, 1990.

Zagury L, Zagury T, Guidacci J. Diabetes sem medo. Rio de Janeiro: Rocco Ltda, 1986.

\section{Tema 2: Atenção nos serviços de saúde}

Objetivo Geral: Desenvolver atitudes de autoconfiança e perseverança no atendimento à sua saúde.

\section{Objetivos especificos:}

- identificar os diversos serviços de saúde e instituições que desenvolvem o atendimento ao diabético, no município; 
-descrever os seus direitos à saúde,

- conhecer os direitos e deveres dos serviços de saúde, assegurados em lei.

\section{Conteúdo Programático:}

Plano municipal de saúde de Uberaba.

Lei orgânica da saúde.

\section{Estratégias de ensino:}

- solicitar ao grupo que relacione as principais dificuldades sentidas no atendimento à saúde, determine suas causas e apresente propostas de solução;

- apresentar ao grupo um croqui do mapa municipal, destacando os serviços de atenção ao diabético, bem como suas características;

- fornecer uma cartilha contendo os direitos e deveres dos serviços de saúde e os direitos do cliente para ser trabalhado em grupos pequenos;

- solicitar a esses traçarem um paralelo desse material com as sugestões apresentadas inicialmente,

- socializar os resultados obtidos.

\section{Referências Bibliográficas:}

Secretaria Municipal de Saúde. Proposta do plano municipal de saúde. Uberaba: 1993.

BRASIL. Lei orgânica da saúde. Lei n. 8080 de 19 de setembro de 1990, dispõe sobre a organização dos serviços de saúde. Conselho Nacional de Secretários Municipais de Saúde, v.2, 1990.

\section{Tema 3: Doenças associadas}

Objetivo Geral: Compreender as enfermidades que mais acometem os diabéticos, possibilitando a reflexão sobre a sua situação de saúde.

\section{Objetivos especificos:}

- identificar as enfermidades que mais acometem os idosos diabéticos;

- discorrer sobre as ações promocionais e preventivas dessas enfermidades,

- relacionar a interferência de doenças múltiplas no controle e tratamento do diabetes mellitus.

\section{Conteúdo Programático:}

Noções básicas sobre: hipertensão arterial, insuficiência cardíaca, catarata, glaucoma, chagas, artrose, insuficiência renal.

\section{Estratégias de ensino:}

- listar as doenças associadas presentes nos membros do grupo;

- solicitar ao grupo, que apresente verbalmente o que conhece sobre tais enfermidades;

- exposição dialogada, pelo coordenador do grupo, sobre as enfermidades e formas de prevenção e recuperação;

- respostas às dúvidas;
- dividir os idosos diabéticos em grupos menores e solicitar que discutam a interferência destas enfermidades no controle e tratamento do diabetes,

- socializar os resultados.

\section{Referências Bibliográficas:}

Brunner L, Suddarth DS. Tratado de enfermagem médico cirúrgica. led. Rio de Janeiro: Guanabara-Koogan, 1993.

Rios MG. Diabetes en el senescente. Rev Med Chile 1992; 120: 593-601.

\section{Tema 4: $O$ idoso diabético}

Objetivo Geral: Possibilitar ao idoso diabético voltar-se para si mesmo, examinando o momento que está vivenciando.

\section{Objetivos especificos:}

- identificar as principais modificações que ocorrem no envelhecimento; sentindo

- relacionar tais modificações com as que estão

- discorrer sobre o papel da familia no apoio ao idoso.

\section{Conteúdo Programático:}

Alterações fisiológicas, psicológicas e sociais do envelhecimento.

A familia e o idoso.

\section{Estratégias de ensino:}

- solicitar ao grupo que desenhe em uma folha o "envelhecimento";

- solicitar a cada membro que apresente seu desenho ao grupo e verbalize sua percepção;

- utilizando-se dos sub-temas emergidos nos desenhos, fazer uma exposição dialogada sobre o envelhecimento;

- dividir os sujeitos em dois grupos e solicitar que o primeiro apresente uma figura de uma família com idoso e o segundo uma figura de uma família, estando o idoso separado;

- solicitar aos grupos que discutam o que representa a figura, relacionando-a à sua vida;

- socializar os resultados,

- a partir dos resultados apresentados, o coordenador do grupo destacará o papel da família no apoio ao idoso,

\section{Referências Bibliográficas:}

Waldow VR. O papel da enfermagem na velhice, face às modificações fisiológicas e fisiopatológicas. Rev Paul Enf 1984; 4(4): 127-31. 


\section{CONSIDERAÇÕES FINAIS}

Ao apresentar o atual contexto de saúde dos idosos e o impacto do diabetes mellitus na saúde deste grupo populacional, verifica-se que esta temática abre um leque de possibilidades para as ações do enfermeiro, que somam-se às de outros profissionais e contribuem para reverter o quadro identificado de agravos à saúde.

Dentre as ações em saúde, ressalta-se a necessidade de preparo de profissionais de saúde atentos aos fatores de risco do diabetes mellitus tipo 2. Além disso, as atividades para os idosos devem ser propostas em consonância com os objetivos da prevenção da doença e promoção da saúde.

A partir dos temas geradores, elaborou-se uma proposta educativa, baseada no modelo de educação conscientizadora de Freire (1993), que levasse o idoso a refletir sobre a interferência do diabetes mellitus em sua vida, bem como as possiveis formas de enfrentamento desta enfermidade, de maneira a não modificar substancialmente seu estilo de vida.

Sentiu-se a necessidade de maior divulgação, pelos órgãos nacionais de saúde, dos sinais e sintomas do diabetes mellitus, verificando-se que muitos idosos descobriram "por acaso ", o diagnóstico desta enfermidade, mesmo apresentando seus sintomas. Atenta-se para o fato de que alguns idosos só descobrem que estão com diabetes ao apresentarem as complicações crônicas advindas, em geral após vários anos de instalação da doença.

Atualmente, vivencia-se um aumento tanto na expectativa de vida, quanto na maior incidência das doenças crônicas não transmissiveis. Considera-se, pois, fundamental que os profissionais de saúde, em especial o enfermeiro, direcionem sua prática profissional para ações que levem à independência, à autonomia e à qualidade de vida aos idosos. Para tanto, é necessário ampliar, cada vez mais, o conhecimento sobre o envelhecimento, as doenças crônicas e os fatores que têm determinados melhores ou piores condições de saúde e qualidade de vida. O enfermeiro deve estar atento às mudanças que estão ocorrendo no país e no mundo, para que possa adequar seu conhecimento teórico-prático às reais necessidades de saúde da população.

\section{REFERÊNCIAS BIBLIOGRÁFICAS}

(1) Laurenti R, Fonseca LAM, Costa Jr ML. A questão demográfica e a transição epidemiológica. In: 1990 set 2-6; Campinas. Campinas: Unicamp; 1990. p. 143-165
(3) Rios MG. Diabetes en el senescente. Rev Méd Chile 1992; 12: 593-601.

(4) Martins IS, Coelho LT, Mazzili RN, Singer JM, Souza CU, Antonieto Junior $\mathrm{AE}$ et al. Doenças cardiovasculares, ateroscleróticas, dislipidemias, hipertensão, obesidade, diabetes mellitus em população da área metropolitana da região sudeste do Brasil. Rev Saúde Pública 1993; 24(4): 250-261.

(5) Laurenti R, Fonseca LAM, Costa Jr ML. Mortalidade por diabetes mellitus no município de São Paulo (Brasil). Evolução em um período de 79 anos (1910-1978) e análise de alguns aspectos sobre associação causais. Rev Saúde Pública 1982; 16:77-91.

(6) Lessa I. Epidemiologia, assistência médica e impacto econômico e social das doenças cardiovasculares e do diabetes mellitus. Inf Epidemiol SUS 1993; 2(4): 05-32.

(7) CENEPI Estudo multicêntrico sobre a prevalência do diabetes mellitus no Brasil. Inf Epidemiol SUS 1992; 1(3): 45-73.

(8) Ministério da Saúde (BR). Diabetes mellitus: informe técnico. Brasilia; 1993.

(9) Ministério da Previdência e Assistência Social (BR)- Política nacional do Idoso: perspectiva governamental. Brasília; 1996.

(10) Coles C. Educating the health care team. Patient Educ Couns 1995; 26: 239-44.

(11) Freire P. Pedagogia do oprimido. Rio de Janeiro: Paz e Terra, 1993.

(12) Napalkov N. The role of the World Health Organization in promoting patient education with emphasis on chronic diseases. Patient Educ Couseling 1995; 26: 5-7.

(13) Domingues JL. O cotidiano da escola de $1^{\circ}$ grau: o sonho e a realidade. [Tese] São Paulo (SP); Pontificia Universidade Católica de São Paulo; 1985

(14) Veras RP Pais jovem de cabelos brancos: a saúde do idoso no Brasil. 2 ed. Rio de Janeiro: Relume Dumará/UERJ; 1994.

(15) Withnall AME, Kabwasa NO. Education for older adults. In: Titmus CJ. Lifelong education for adults: na international handbook. Oxford: Pergamon, 1989. p. 319- 312.

(16) Milligan F. In defense of andragogy. Nurse Educ Today 1995; 15(1): 22-27.

(17) Ferreira $\mathrm{ABH}$. Minidicionário da língua portuguesa. Rio de Janeiro: Nova Fronteira, 1993.
Artigo recebido em 21/02/00

Artigo aprovado em 09/01/02 